\title{
The Outside In: The intensification of landscape in the Anthropocene
}

\author{
Jacqueline Mclntosh, Bruno Marques, Madeleine Palmer, and Verarisa Ujung
}

\begin{abstract}
Degradation of ecosystem services, scarcity of resources and the erosion of the planet's capability to absorb waste is of immediate concern. This situation is novel in its speed, its global and local scale and its threat to the planet and its people. Inspired by the recent discourse of the Anthropocene, this paper explores the convergence of human and nature as they confront generative and destructive forces in two distinctly different settings. Using a case-study approach, this paper adopts the cyborg landscape as a conceptual framework to address the interconnectedness of systems, and scale and poetic brief to accommodate the environment while supporting the needs of our contemporary society. By using nature's generative capacities as well as its destructive tendencies and by blurring the disciplinary boundaries between interior architecture and landscape architecture, this paper considers two different locations in New Zealand: a post-industrial site on Auckland's urban waterfront and a remote active volcanic site located on White Island. It finds opportunity to examine intensified inhabitation through acts of immersion and extraction in the "new normal" where nature's interrelated systems and the artifice of the Anthropocene create innovative and dynamic possibilities. It concludes that the creation of a link between natural processes and responsive technologies can provide solutions to address the complexity of climate change.
\end{abstract}

Keywords: Anthropocene, intensification, cyborg landscapes, interiority, responsive technologies

\subsection{Introduction}

The balance that has existed between human and nature for thousands of years has been disrupted with the era of the Anthropocene, affecting not only our fragile, natural ecosystems but also our built urban infrastructure. Creating a complex relationship between nature and built environments, human intervention is now considered to be the dominant influence on geological, atmospheric, and ecological processes (Turpin 2014). Defying easy classification, the Anthropocene has been loosely defined as an

Stable URL: https://arcc-journal.org/index.php/arccjournal/article/view/445 10.17831/enq:arcc.v16i1.445

Corresponding Author: jacqueline.mcintosh@vuw.ac.nz

Published by the Architectural Research Centers Consortium under the terms of the Attribution-NonCommercial-ShareAlike 4.0 International license epoch that accepts "that human activities have significantly changed Earth system processes [and forms] during the last [few] ... centuries" (Rull 2013, 4) and "humankind has become a geological force in its own right" (Steffen et al. 2011, 843). However, "unlike like earlier movements, all theories of the Anthropocene are premised on the historical notion of an absolute break with the past: a hypothetical point in time when the human condition is irrevocably changed" (Boas and Marshall 2014, 62). 
Not surprisingly, the implications of the Anthropocene are much discussed and debated across a range of natural science disciplines as well as those in social sciences, humanities and arts. Collective cross-disciplinary discussion has provided the intellectual context for the Anthropocene hypothesis (Castree 2014a) as well as concerns regarding a false sense of separation between people and the non-human world which can be commonly found in dualisms such as rural-urban, nature-culture or society-environment. There is widespread agreement that the advent of the Anthropocene calls for a fundamental re-think of some of the most elemental categories of Western thought and how we might then act in the world.

In this vein, seminal historian Chakrabarty (2009) calls for a new set of conceptual tools that can allow the description of human agency as a geophysical force. Similarly, philosophers, cultural theorists and artists also acknowledge the imperative for novel questions, new forms of enquiry, new methodologies, and new agendas for political engagement, as the social, political, and physical parameters change faster than our capacity to process and analyse them (Johnson et al. 2014, Boas and Marshall 2014). The re-making of the future across scales and sites of production, using alternative forms of enquiry (Lehman and Nelson 2014) such as site-specific collage and assemblage, enables a critical and creative framing of the context.
The epochal shift marked by "human-generated 'forcing mechanisms' in the face of climate change, oceanic acidification and wide-spread land use changes with their resultant habit disruptions" needs to be explored and interpreted (Dalby 2014).

As the repercussions of these changes impact human and natural environments, architects and designers of all kinds need to actively broach the divide between man and ecology. In addition to a consideration of the creation of ecological and atmospheric processes, geological shifts can create an intertwining of humans and geology through destructive events. A complex oscillation occurs between the destruction and the creation of the natural and human environments. The response similarly fluctuates from those who predict future ecological chaos and attendant international conflict to the 'hyper-modernizers' who would seek to ramp up human efforts to maintain and control the biophysical environment (Johnson et al. 2014). Using technology as an opportunity to harness nature's generative capacities, emerging concepts such as those of cyborg landscapes and responsive technologies show potential to bridge the junction between the forces of nature and that created by man. Yusoff (2013) and Clarke (2011) both extend and challenge existing research into the 'more than human' as they call for an expanded sense of the nonhuman in 'scope and scale' and the sober recognition of human frailty. Cyborg landscapes, unlike
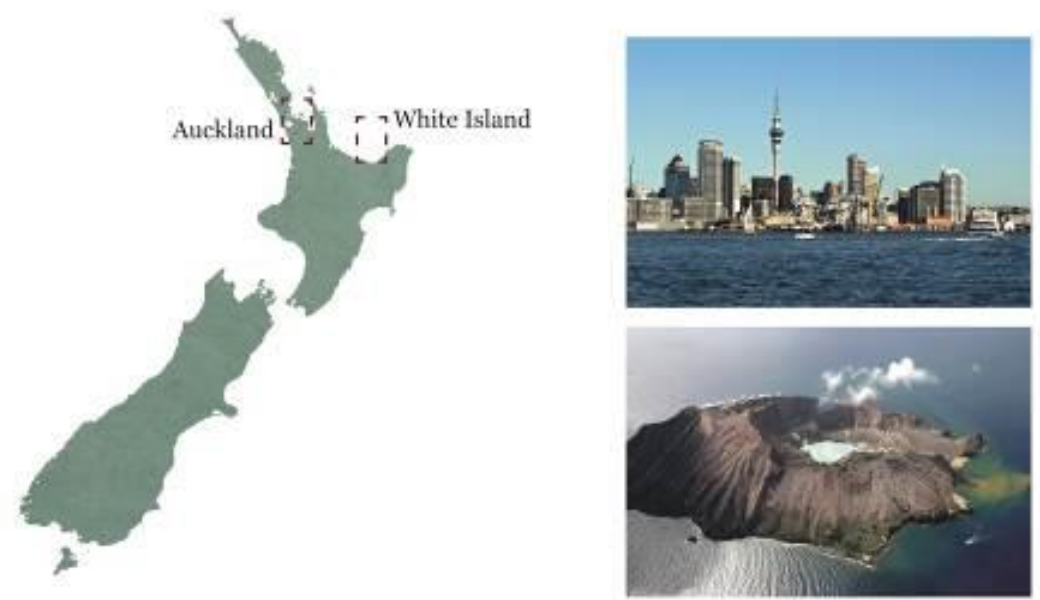

Figure 1: Location of Auckland's waterfront and White Island. 
responsive landscapes, are dynamic, affecting change and actively shaping new relationships and feedback mechanisms between biotic and abiotic systems (Lokman 2017).

"The advent of the Anthropocene presents a conjuncture: a moment pregnant with risks as well as generative opportunities" (Johnson et al. 2014, 440). The continuous transformation demands an understanding of forces both as pragmatic imperative and as poetic brief for a new Anthropocenic art that can "move beyond this description and into a new realm of 'ecodiegesis' that can give voice to the planet itself" (Boas and Marshall 2014, 64). To examine the design implications of these new ideas, two seemingly opposite sites in New Zealand have been selected for exploration: the post-industrial Auckland waterfront and the remote volcanic tourist attraction, White Island (Figure 1). The first explores opportunities to cultivate natural energies and forces through the use of technology to provide not only resources for the city but to allow for an intensification of the human experience within our built environment. Auckland as a highly urbanized, 'spoiled' natural environment necessitates the investigation of multi-purpose, resource-producing public spaces through the adoption of clean technologies such as renewable power generation, biofuels and water remediation. In contrast, White Island is the location of an active volcano where new landscapes are dynamically created, a violent creative and destructive example of the power of nature which has become an important visitor experience. This case study explores opportunities for architecture to frame and thereby intensify human experience, artificially creating a boundary between outside and inside as well as providing opportunity for reflection on the magnitude of the powers leashed. These two very different sites offer the opportunity to showcase the energy, power, fluctuation and forces of nature and the artificial and their ability to intensify the human experience at various scales.

A change of environment is also evident in the disciplines engaged with the study of the impact of this global human activity. Scholarly work produced in the last decade has blurred the boundaries and transgressions into what had been perceived as the territories of the 'Other'. More specifically, the disciplines and professions of landscape architecture, architecture and interior architecture are no longer defined by clear distinctions and boundaries. Divisions between disciplines are now proving less important than the goals design disciplines share.

\subsection{Methodology}

This research employs a "research through design" structure that investigates both setting and phenomenon through the positioning of theory with two case studies (Lehman and Nelson 2014). To explore the relationship between human and nature as well as generative and destructive forces, an urban setting at Auckland's waterfront and the remote volcanic phenomena, White Island have been selected for design experimentation. The process of examining Auckland's waterfront through the perspective of landscape architecture and White Island through the lens of interior architecture has been used to illustrate how the interconnected system of body, energy and surface engaged through architecture and/or technology can enhance and facilitate human experience. This exploration adopts

\begin{tabular}{|l|l|l|l|l|l|l|l|l|}
\hline \multirow{2}{*}{$\begin{array}{l}\text { Case } \\
\text { Studies }\end{array}$} & $\begin{array}{l}\text { Interior } \\
\text { Architecture }\end{array}$ & $\begin{array}{l}\text { Landscape } \\
\text { Architecture }\end{array}$ & $\begin{array}{l}\text { Human } \\
\text { and } \\
\text { Nature }\end{array}$ & $\begin{array}{l}\text { Generative } \\
\text { and } \\
\text { Destructive } \\
\text { Forces }\end{array}$ & $\begin{array}{l}\text { Body, } \\
\text { Energy } \\
\text { and } \\
\text { Surface }\end{array}$ & $\begin{array}{l}\text { Impact of } \\
\text { Technology }\end{array}$ & Pragmatic & Poetic \\
\hline $\begin{array}{l}\text { Auckland } \\
\text { urban } \\
\text { waterfront }\end{array}$ & - & $\checkmark$ & $\checkmark$ & $\checkmark$ & $\checkmark$ & $\checkmark$ & $\checkmark$ & \\
\hline $\begin{array}{l}\text { White } \\
\text { Island }\end{array}$ & - & - & $\checkmark$ & - & $\checkmark$ & $\checkmark$ & & $\checkmark$ \\
\hline
\end{tabular}

Table 1: Summary of the theoretical lenses and their application in the case studies. 
strategies that investigate links between the outside and the inside to illustrate the importance of theory development in the experimental design research approach. In this way, the research adopts a macroto-micro strategy with respect to theoretical exploration as the Anthropocene presents an occasion for critical design thinking to reconnect with macro scale concerns in a way that escapes the ideological generalisations of globalization (Yusoff 2013). Conversely, the case study explorations adopt a micro-to-macro design approach to explore smaller scale site specific engagements which consider the deep ramifications of anthropogenic environmental change by examining the planet's material opportunities (Clarke 2011). Iterations of site-specific strategies can thereby be formulated as a research tool to experiment with scale and boundaries within each of the case study sites to create an interconnected relationship between mechanic systems and natural processes (Dalby 2014, Johnson et al. 2014).

Taking this theoretical foundation and applying it to two diverse locations, framed through different disciplinary lenses, can be a strategy for exploring and testing theory and design of the relationships between human and nature (Castree 2014B); generative and destructive forces; body, energy and surface; and the impact of technologies on our environment (Table 1). Starting with the conventional distinction between the two disciplines, Auckland's waterfront has adopted a macro-to-micro approach, starting with consideration of the wider urban context, then narrowing the interventions to specific sites. In contrast, White Island has been examined using a micro-to-macro scale, obtaining a view limited to the range of an individual's field of vision, then figuratively stepping back to frame that view to separate inside from outside and intensify the experience. In this manner, both projects consider the use of techniques adopted from the two design disciplines, either to respond to the larger context or to adapt to the smaller spaces within the design. These differing speculations are essential to fully explore the use of technology, utilizing natural energies and providing the opportunity to design with nature's interrelated systems.

\section{TWO CASE STUDIES}

\subsection{Auckland's waterfront and the cyborg landscape}

The Anthropocene has been defined as a period where global human activity has deep consequences for environmental change (Lewis and Maslin 2015). As environmental changes begin to have negative impacts upon environments, there becomes an imperative for adaptation and for infrastructure design to respond to the accompanying issues. Future generations may be unable to use ecosystems in a sustainable manner due to the decrease of natural resources (Lokman 2017). Only the blending of machines and nature into cyborg landscapes appear to be able to begin to alleviate some of the pressure on these natural systems.

The increasing pressures on our cities caused by a growing worldwide population and a scarcity of resources, stress the importance of creating an adaptable urban environment with dynamic interactions between the creation of resources and public space with the built environment. Within the Auckland waterfront area, the Wynyard Quarter is a good example of a post-industrial waterfront landscape which has been most recently transformed by new urban development. It forms a boundary between the central business district and the waterfront. With sea level rise, this area is expected to flood (Auckland City Council 2017) creating a unique marine/urban environment (Figure 2). Traditionally, humans leave the sea to its own devices, and while actions on land affect the sea's ecosystems, it is generally ignored with the exception of the threshold occurring between the sea and land. The creation of this new hybrid ecosystem provides an opportunity to consider the merger of man and nature through the use of technologies.

Through this case study, the integration of clean technologies into public space has been explored through a term Lokman (2017) refers to as a cyborg landscape. A cyborg landscape has been defined as a landscape which consists partly of mechanical systems and partly of natural processes, however it is the relationship between these two components that classifies a landscape under this term (Lokman 2017). Responsive landscapes, a term coined by Cantrell and Holzman (2016), also explores the integration of robotic devices in a landscape context using technology to simulate or visualize biophysical processes and climatic phenomena within a public 


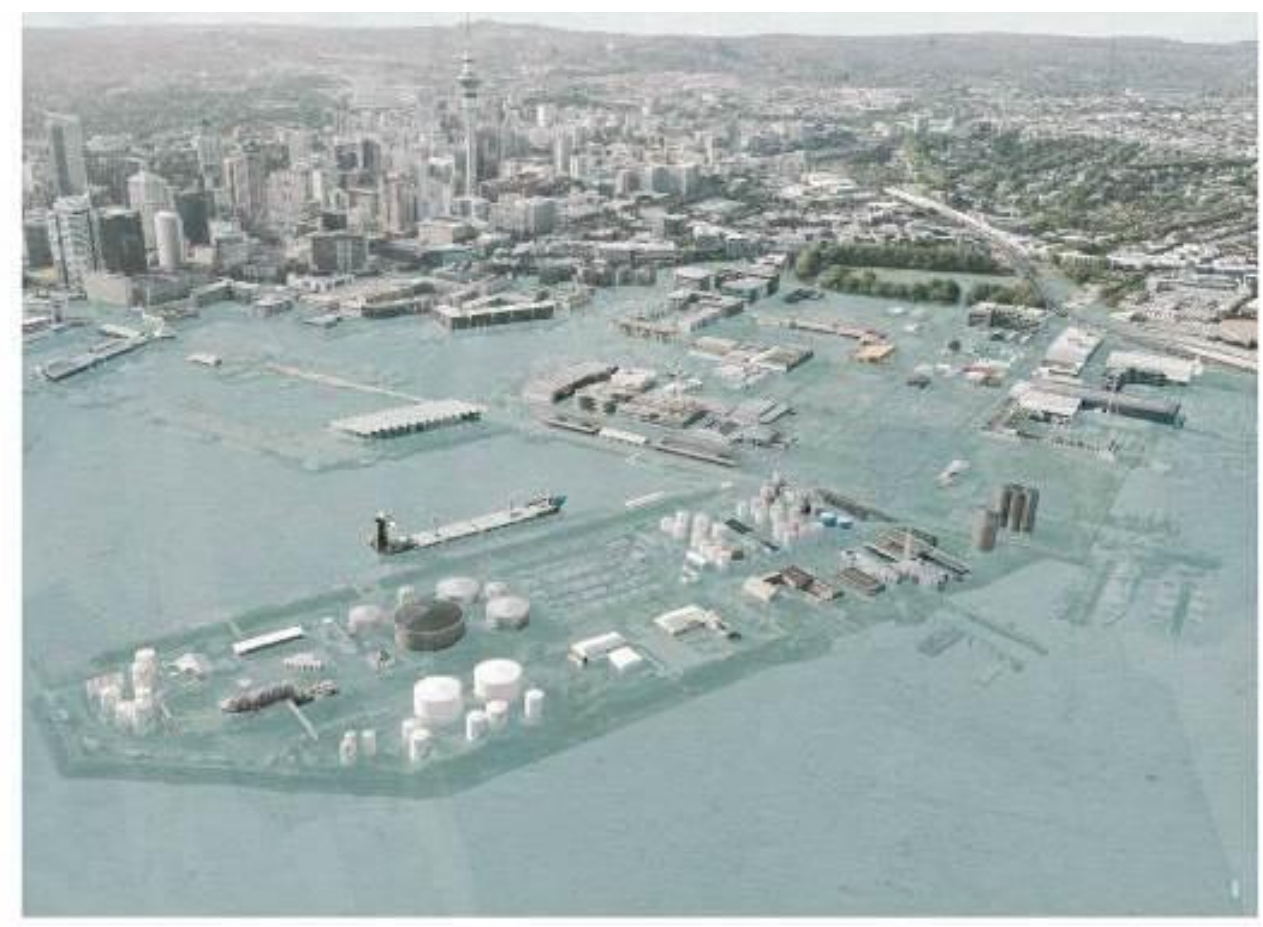

Figure 2: Modelling of 3-meter sea level rise at Auckland's waterfront.

space. However, Lokman (2017) distinguishes cyborg landscapes from responsive landscapes "because cyborgs are dynamic, affecting change and actively shaping new relationships and feedback mechanisms between biotic and abiotic systems" and "...responsive landscapes do not directly affect or change these systems" (63) (Figure 3).

Lokman (2017) maintains that cyborg landscapes create socio-environmental and spatial conditions that anticipate change with nature-culture relationships that have high flexibility and pre-adapt to even slow change over time. This idea of preadaptation has been linked to contemporary understandings of sustainability through the "strength of mutual reinforcement between processes, incorporating both the ability of a system to persist despite disruptions and the ability to regenerate and to maintain existing organization" (Gunderson and Pritchard 2012, 6). Cyborg landscapes do not just fit their surroundings, they affect the environment in various ways through builtin and feedback mechanisms which allow them to respond and adapt as a result of an ongoing interaction. Parrot and Meyer (2012) take this further acknowledging that the nature of complex systems at local, regional and global scales are intertwined and always interacting, as the changing conditions at one scalar level can trigger the emergence of processes and the relationships in the other. To illustrate a connection between machines and nature, Lokman (2017) analyses Oyster-tecture, developed by Scape Landscape Architecture. This landscape creates relationships between living and non-living organisms and humans and non-humans to be cultivated through the creation of recreation spaces and new intertidal habitats (Lokman 2017). However, Oystertecture places these interventions into an existing marine environment, rather than responding to the flooding of an urban environment.

Open public space can address the prospect of linking the marine ecosystem with the cityscape through the development of a cyborg landscape. Merging this concept with sea level rise challenges existing ways of thinking about infrastructure and climate change. It nurtures the development of new relationships between buildings, urban design and the landscape. It also fosters new design opportunities for architecture as the flooded cityscape becomes a marine environment. 


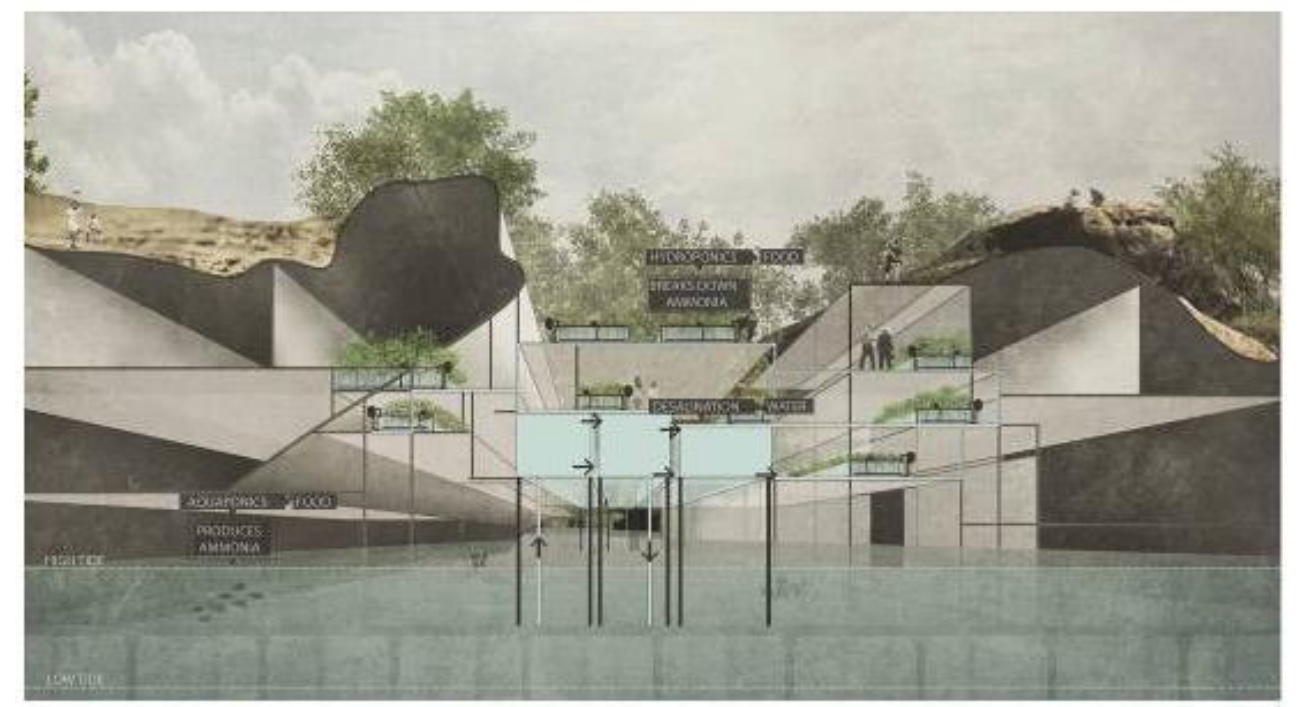

Figure 3: Hydroponics, aquaponics and desalination of water are proposed for Auckland waterfront, located between buildings and formed through the walkway structure.

Cyborg landscape and the use of clean technologies can be used in public space to inform the public, address resource concerns and demonstrate how technology can provide resources for the future city. In the context of the waterfront, a variety of energy sources such as tidal energy, solar power and wind offer the greatest potential for exploitation. Figure 4 illustrates how the intensification of these energies can be both explorative and generative and create physical boundaries, surfaces and edges to define space.

In another design iteration, and taking inspiration from the structure of a coral reef and the way it supports a variety of ecosystems, algae technologies have been developed into a system which provides both a framework for open public space, but also a platform for other technologies within its system. Utilizing light, carbon dioxide and wastewater,

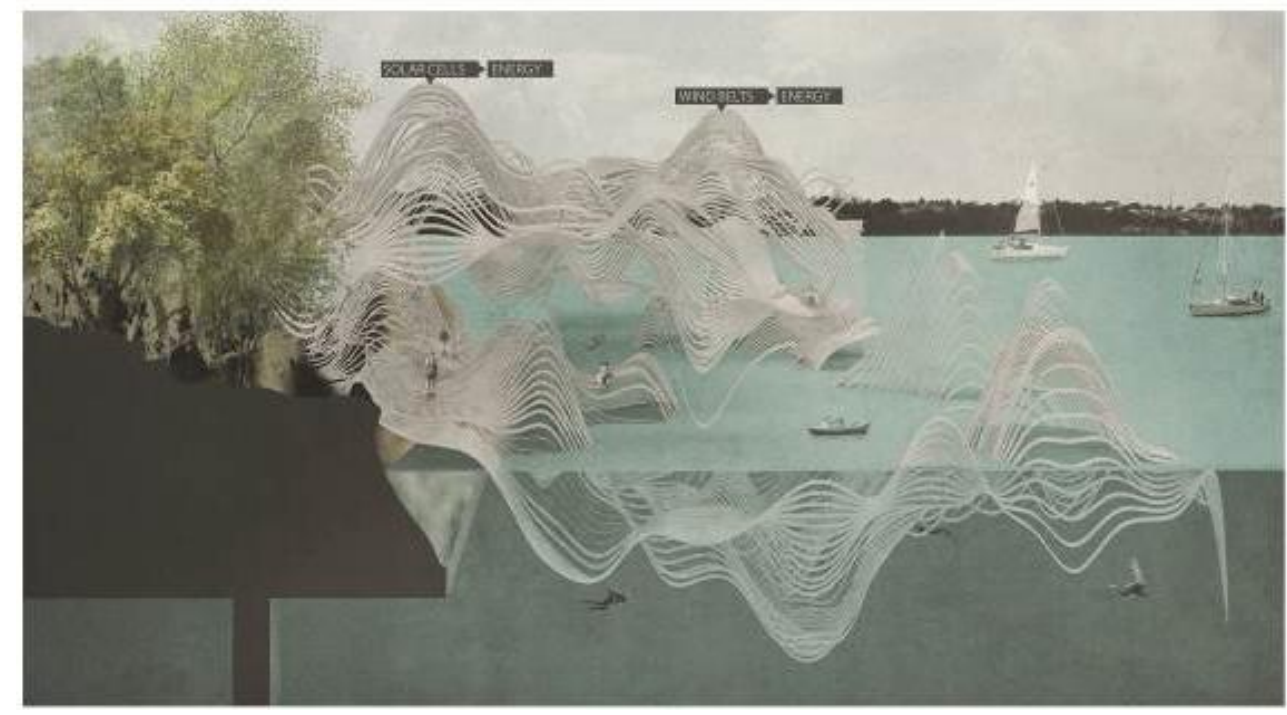

Figure 4: Solar, wind and tidal energy sources. 


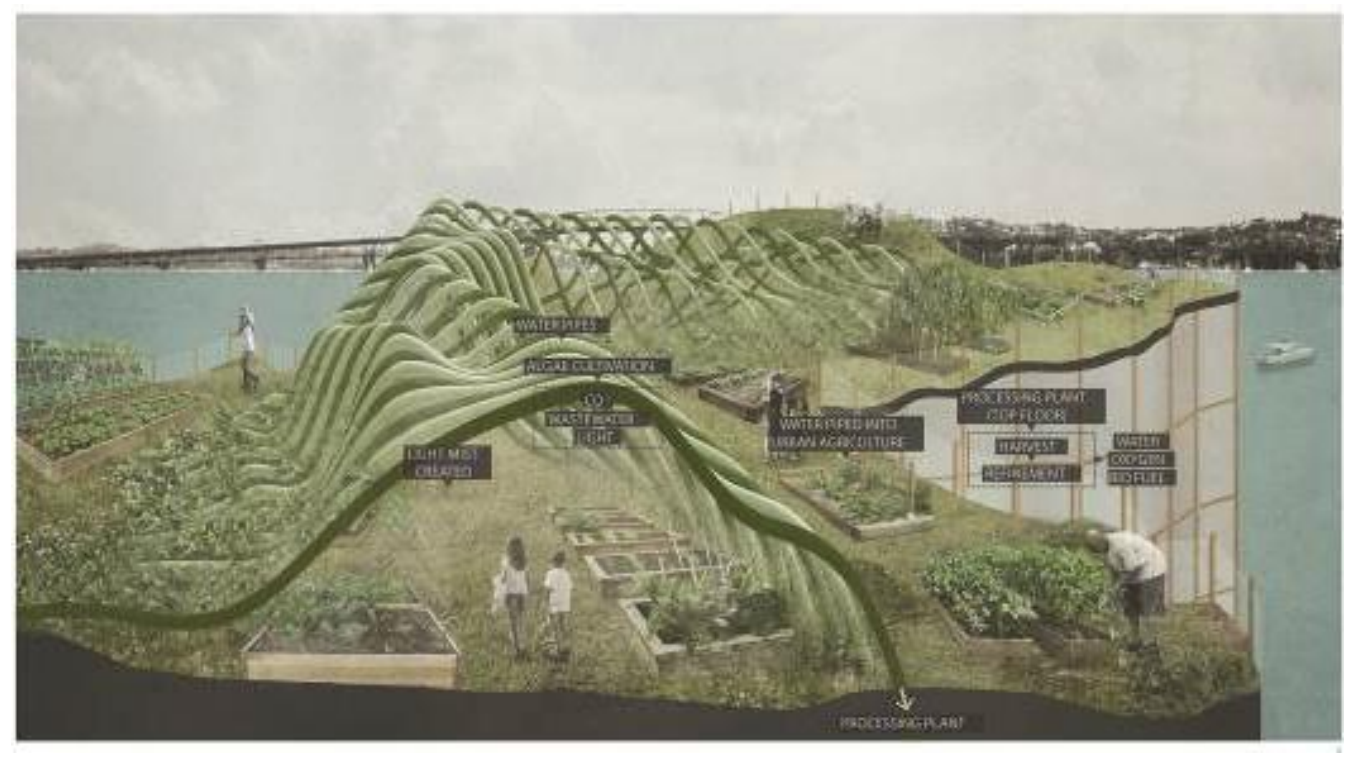

Figure 5: Algae and food production.

greywater and/or stormwater to grow, the algae produces biofuel, oxygen and purifies the water (Figure 5). This biofuel can be converted to energy to use within the city and the water can be used for urban agriculture. Similarly, urban agriculture in the form of hydroponics can be implemented into the algae structures, and other renewable energy generation, such as solar panels and wind turbines, can be adapted to work within this larger system.

Utilizing the sea, the potential of tidal power is also evident as it influences surface and form, implicating both the spatial and temporal scales. Embedded technologies can create both tangible and intangible marine environments; they can facilitate the integration of reefs, protect the shoreline and provide food for the city. They can also provide opportunities for intensification through sensory narratives that capture the embodiment in rich time-space ways. Temporality relates to both the tidal flows which change daily, but also over years as the sea rises. From this epistemological perspective, the waterfront faces on-going challenges associated with the making of smaller, intimate spaces. Techniques used within interior architecture such as the creation of immersive environments (immersion), experience design and extracting visual patterns (extraction) can be adopted to create a relationship between the body and the space, facilitating a human experience, as illustrated in figures 3 to 5 .
The link from the larger landscape to the smaller and the interconnectedness of public spaces is not only created through the body-energy-surface intensification but also through different happenings. These happenings are moments within the landscape that highlight the issues of the larger network within the public space. Through the use of lights, sounds and kinetic forces, attention can be brought to one of the resource-producing technologies that are situated within the space. If a system is not functioning adequately that is due to a disconnection from the larger context. Storms threatening the production of the urban agriculture or increased pressure on energy sources due to extreme weather events or functions within the city would produce a response within the urban environment that would highlight these issues to the users of the site.

In the case of the Auckland waterfront, the cyborg landscape creates socio-environmental and spatial conditions that create energies and can adapt to change. For example, the infrastructure is designed to flexibly adapt through the creation of new interstitial habitats and recreational spaces in order to address the flooded cityscape or rising sea-levels (Figure 3). Similarly, increased volatility of the biophysical environment creates both intensity as well as opportunities for solar, wind and tidal energy. Oscillating ambiguities of scale, fluctuations through flattening and heightening surface and subject 
suggest a new, more intense understanding of everyday urban materials and events. These visual and aural moments of intensification and variation enable the exploration of intimacy in relation to the urban, and suggest an urbanism of heightened sensation, augmented in the imagination with qualities of sound, touch, taste and smell.

The act of intensification involves the release of energy and is dependent on surfaces and services, yet has generative capacities when energy is transitioning from one state to another (Lally 2009a). The discussion of the act of intensification in this study is generated by the relationship between energy and materiality, and spatial and temporal scales, of relevance for observing energetic exchanges. There are various forms of energy such as electromagnetic, thermodynamic, acoustic, and chemical, which are controlled and manifested as set of materials for constructing physical boundaries that define space (Lally 2014, Moffitt 2013). The human intensity results from the new relationship between body and space, resulting from potential immersion in new forms of extraction architecture (Figure 4). New methods of food production permit circular systems to be introduced such as that associated with aquaponics and hydroponics (Figure 5). These examples illustrate the crucial built-in feedback mechanisms that respond and adapt to on-going interaction between nature and machine. They also blur the boundaries between blue and green infrastructure, creating interstitial spaces that flexibly mediate between the two.

Leading the way into the future, this approach is considered essential to exploring how we will continue to survive on this planet (Lokman 2017). Without considering new methods for achieving planetary stewardship, humans will no longer be able to survive within the toxic environment they have created on Earth. A new relationship between our built environment and the natural environment could be bridged through a reconsideration of how technologies can be used within architecture. Shaping new relationships is essential to responding to a constantly fluctuating environment.

\subsection{White Island/Whakaari and Energy as Poetic Brief within the Act of Intensification}

White Island is an active volcano located off the east coast of New Zealand's North Island. Currently uninhabited, the historic sulphur factory was destroyed by a volcanic eruption and has been left in ruins, a harsh reminder of the destruction nature can cause. Emitting various forms and intensities of subnatures (smoke, mud and sulphur gas), this case study explores form, materiality and pattern to determine the significance of including the wider ecological processes within an interior space (Gissen 2009). In this manner, 'material energies' of thermal variation, air velocity, light spectra, as intensified versions of the energies already around us, can be both explorative and generative. They can be engaged to create physical boundaries, surfaces and edges to define space, facilitate activities, organize hierarchies, provide security, and produce architectural shape that can inform the body's behavior (Lally 2014). These thermal or thermodynamic boundaries, which are defined as actions rather than tangible things, can be understood as behaviours where energy transfers and exchanges form, and which in turn act upon the environment (Addington and Schodek 2005). The boundaries created act as a place of friction, facilitating energy transfer and providing the possibility to promote the connection of body, energy and surface.

As Addington and Schodek (2005) suggest, thermodynamic boundaries are zones of activity with diverse yet unique collection of actions:

"Any entity that produces heat within surroundings of air will exchange its heat through buoyancy. In addition, any time there is a difference in temperature between a surface entity and the surrounding air, there will be a buoyant boundary layer... the interior thermal environment, rather than being a singular bounded state, is a large collection of buoyant behaviors, all of which have unique boundaries." (63).

These unique behaviours act more as gradients of intensity not as stationary lines or surfaces that the human body can perceive. In the application of technology and mechanical systems, the boundary operates as the fundamental transition zone for mediating the change between two or more variables. Addington and Schodek (2005) suggest: "this mitigating boundary occurs at all scales, from that of the atmosphere to a microchip, and it is fundamentally responsible for the thermal well-being of the human body." (52) 
Similarly, Fernández-Galiano (2000) suggests that without energy there are no processes or transformations. Within the Anthropocene, the continuous transformation demands the understanding of energy as poetic brief, one that does not produce objects but rather relationships to context - intensification. As such the emergence of energy as poetic brief can give form and order to the space we inhabit.

Such materialities - the shifting intensity and variability of spectra of light, thermal diffusions and transfers, levels of relative humidity, and even our range of olfactory sensitivity - come into existence when we act upon them and give them organizational responsibilities. (Lally 2009a, 9).

Within the act of body-energy-surface intensification, the relationship of their interconnectivity can be explored. This includes the connection between the thermal properties, forms of energy, environmental variables, with informed human behaviour. Lally acknowledges these as directed movement and defined spatial hierarchies (Lally 2014), which he explores in his installation Wanderings. Wanderings engages existing energy systems within surrounding environments, then intensifies and fortifies them to become architectural materials. Lally suggests that "the intensification of the environmental context that the body moves through creates a layered makeup of particulates working together in parallel, overlapping with and integrated with one another" (2014, 64). This prototype addresses the architecture of material energies - the multiple spatial microclimatic zones resulting from discrete objects that are aggregated based on the radii of the material energies. Encountering the ideas of the intensified control and the advancement of material energies to define geographical boundaries, this project also suggests the new potential of architecture to increase the sensory sensitivity of the human body.

Rahm (2017) explores concepts of directed movement, spatial hierarchy and thermal boundaries within the design of Jade Eco-Park in Taiwan. In Jade Eco-Park, the design explored particular atmospheric parameters and their variations of intensity throughout the park, overlapping and interacting with one another. This project demonstrates how interconnected systems between geographic entities, schematic and interrelated micro-climates and the accompanying micro-narratives can create an interconnected system of intensified body, energy and surface.

Testing the idea of energy as poetic brief within the act of intensification in the White Island context generates certain mechanisms and parameters in which the design can operate. The invisible and unique properties of material energies that are calibrated to the body create a sufficiently rich variety of paths embodied in each micro-narrative, architectural shape and frame, and aesthetic value. The adaptation of the energy to accommodate the health tourist's search for recovery from asthma within these microclimates and ecosystems is proposed by the authors as an important part of the design intention. Alternating sensory perception is required to perceive the material energies such as the fumes and the benefits of the atmosphere as it

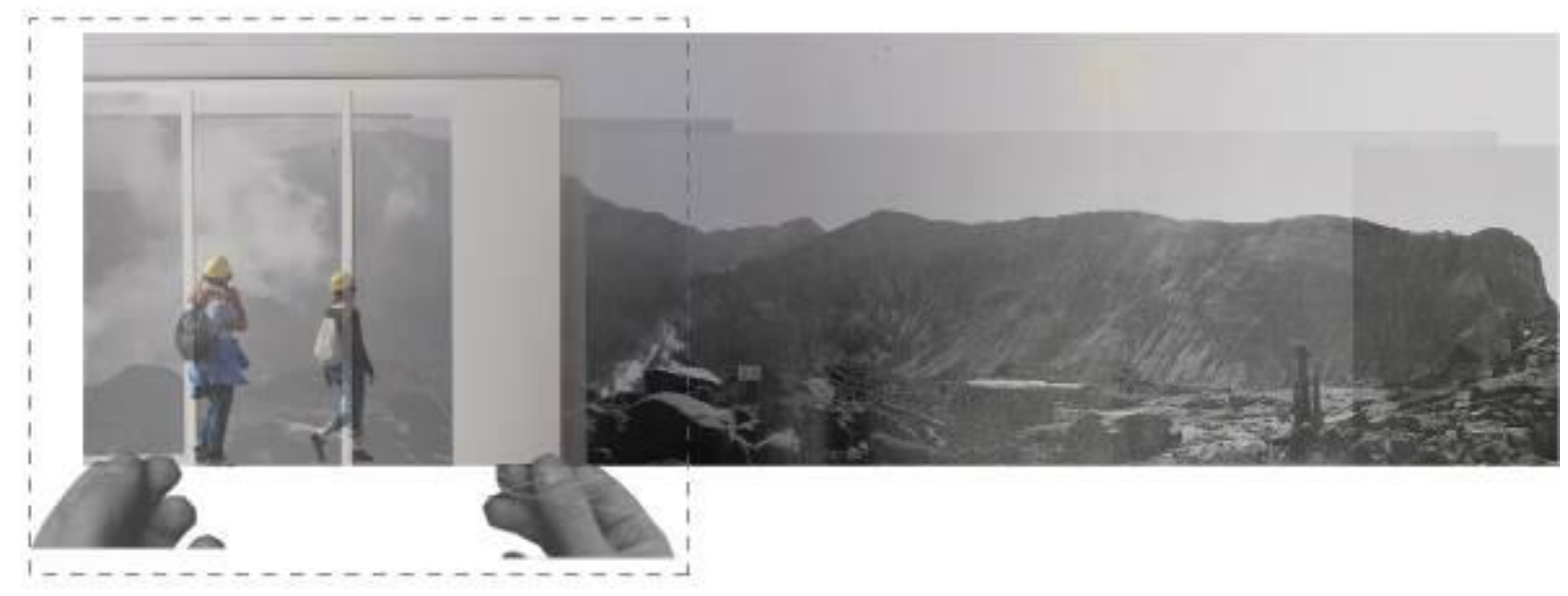

Figure 6: Framing as intensification of thermal boundaries on White Island. 
intensifies, ebbs and flows. The actors, visitor and researcher, as active parts of the system, respond to the environment and its material properties. Here, where the research is concerned with the characteristics of the thermal boundaries between the inside and the outside, body and energy, two different thermal systems can generate multiple spatial zones of activity (Figure 6). These multiple spatial zones must not be regarded as a limit to be transgressed, so much as boundary to be traversed and address the multivalent weathering shifts on site.

As the interior is the best medium to approach the interaction between humans and design, smaller spaces have been created within the larger context of the environment, forming a differentiation between the inside and the outside. Through considering the relationship between the body-energy-surface, the public space design uses interior design processes to begin to create a relationship between the internal and the external. This is essential to provide a spatial experience which is created through the consideration of the how body interacts within its environment and the sensations felt.
Projecting from the projects, Wanderings and Jade Eco Park, to the White Island context, an interconnected system of intensified body-energysurface encounters develop from a series of sitespecific strategies. Figure 7 shows a series of framed encounters along a pathway of discovery. The activation of thermal events that draw from the distinct microclimate conditions of the constructed topography provoke a succession of augmentations that continue as by-products of the primary actions and begin to operate upon the materialities and conditions of the architecture. The experiential design of climatic contexts can produce and manipulate artificial conditions that will carry with them responsibilities. As we mutate, re-appropriate and bastardize these contexts, they become design materials for our organizational as well as aesthetics needs (Lally 2009b). The island's unique habitat, the accessible crater, the acidic environment and the sparse plant growth yield interesting stories, studies, spatial experiences and benefits to the health and wellbeing of the visitors. This consideration of wider ecological processes and how they affect each individual space, suggest that the future of interior depends upon this key relationship, as shown in Figure 8.

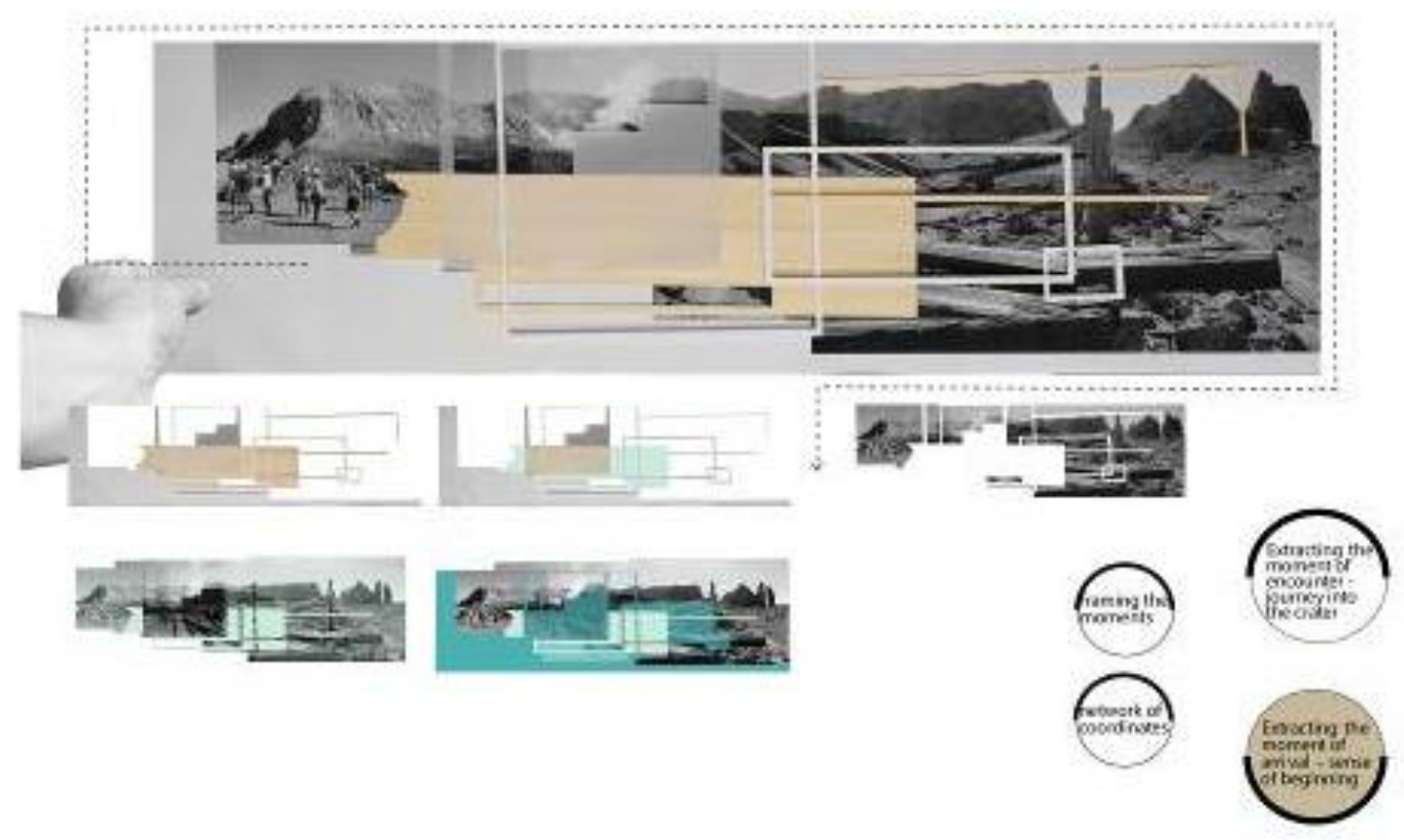

Figure 7: Exploring the relationship between internal and external, tangible and intangible, human and nonhuman qualities. 

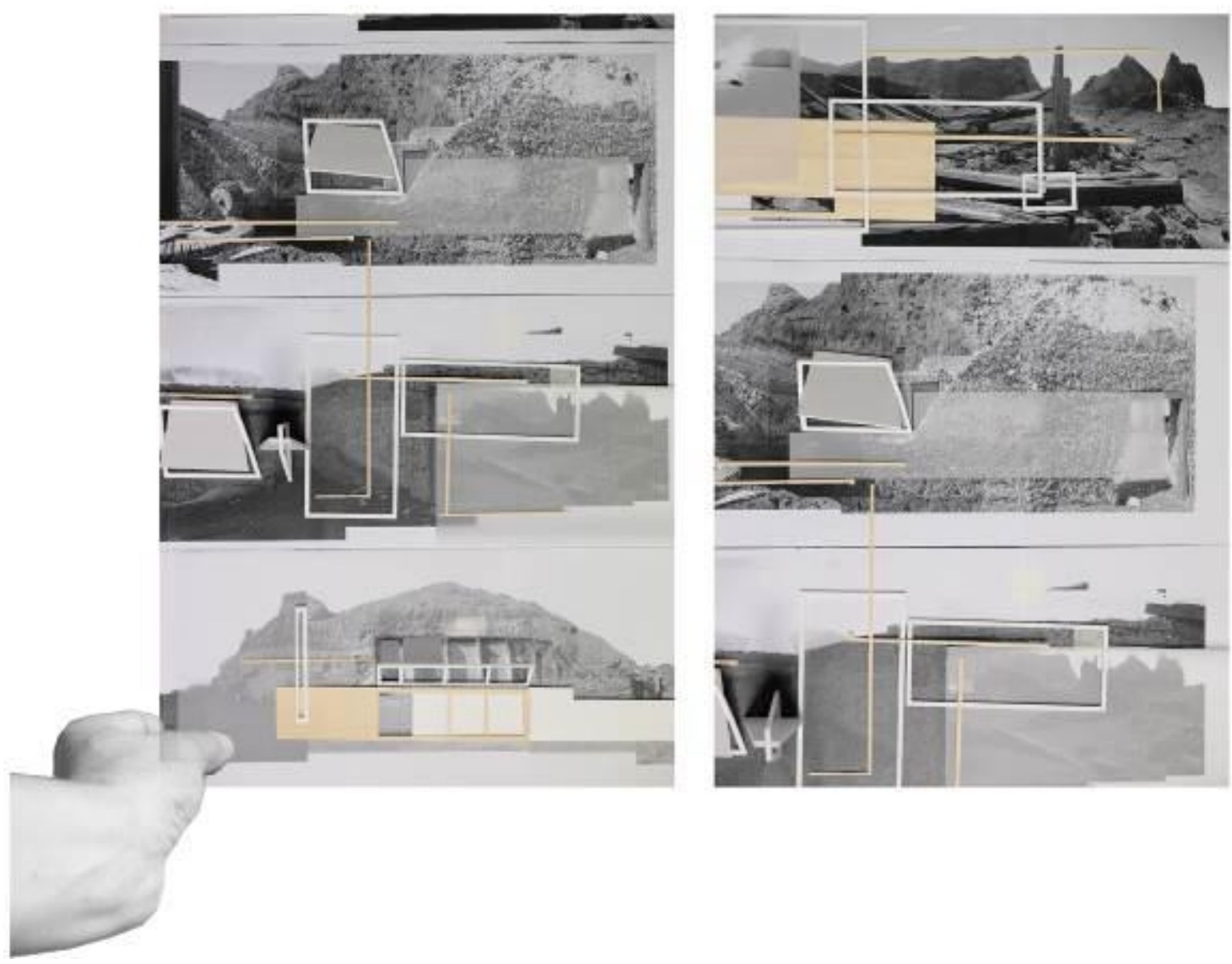

Figure 8: Emphasising the ecological processes and how those aid in generating the design of interior spaces.

The relationship between landscape and interior architecture at its very core is based on the opposition between the outside and inside. "Separating the inside from an outside is the primeval act of Architecture" (Arnheim et al. 1966, 7). This separation can occur in a landscape through the walling off of a garden, or via an interior space through the walls of a building. Arnheim et al. (1966) further discuss this idea of separation, suggesting that architecture creates not only an enclosure but also a sense of order that would not be there without the architect's intervention. Similarly, Blaisse begins to explore interior as a landscape through an installation which brings a landscape into the interior (Weinthal 2008). To achieve this, she increased the scale to create an oversized garden. While some would argue that she has now created a landscape, other would maintain that it is still within an interior space.

The definitions above suggest that all spaces are theoretically interior spaces and Blaisse's installation begins to suggest the idea that the interior is now a landscape. However, there are key elements which separate the two disciplines. The fundamental differences between the two are the relationships that they consider. Interior is defined as the relationship between body and space, textiles and architecture, while Landscape is the relationship between people, space, infrastructure and ecology (Weinthal 2008; Lockman 2017).

Investigating the internal negotiations of the human body and the environment introduces the understanding of interior as the best medium through which to address the interaction between human beings and design (Caan 2011). Caan (2011) looks at interior space as a medium in which the relationship between the internal and the external, the tangible and the intangible, the human and the non-human qualities emerged. In this way, she emphasizes that interior space connects to our being on multiple levels. Considerations of interiority related to our being and our resulting consciousness are addressed in multiple levels within; the intersection of bodily 
conditions (Petrović et al. 2018), sensations (Pallasmaa 2011) and with the affective qualities of spatial experience (Rahim 2010).

In conversation with Davis and Turpin, Grosz (2017) addresses how the intersection between architecture and Anthropocene demands a reconsideration of architecture's temporal qualities that are countered by the notion of embodied and embedded encounter. Similarly, Johnston (2005) suggests that landscape is the background and foreground in which humans are embodied (given body in, given life in), and in which they are embedded (given shape and space), promoting the link between interiority and landscape. In addition, Power (2014) in her investigation on the liminality of interiority also addresses the idea of linking interiority with the landscape in a manner that promotes "embeddedness" as the dominant experience (Benedikt 2002) within the lived narrative.

\section{Discussion}

Often the process of creating boundaries through the distinction of energy is explored on a large scale. Within some of the larger public open spaces, the various forms of energy can create a differentiation between areas to break up the monotony and intensify the user's experience within the key area. This was illustrated in the cyborg environment of Auckland waterfront through different mechanical interventions and in the White Island project through the use of framing to highlight the spatial energies inherent in the landscape. The gradient of intensity ensures periods of quietness among the heightened moments. These heightened areas explore the bodyenergy-surface intensification, engaging with invisible energies such as gravity, heat and wind velocity. When the body is placed within the environment, the three separate entities come together in a relationship to produce an intensity not found in other areas of the site. A narrative is conveyed through the inclusion of the landform and the adoption of a series of interconnected systems at a variety of scales, which create cohesiveness between the elements within the two different projects.

Landscape architects and interior architects share a commonality of issues and processes such as walking and interpreting, making and constructing, preserving and conserving, designing and composing, which have an important mutual resonance with the constructed world and natural forces. This interdisciplinary attitude and thought process reinforces the exploration of several aspects of a shared practice for both disciplines through considerations of site, space, form and materiality. As such, the difference between the disciplines proves to be difficult to distinguish. Beyond the obvious scale factor, landscape designing with the macro and interior designing with the micro, and one defined as outside and the other as inside, the boundaries can quickly begin to blur. Landscape architecture also considers a human-scale and an interior space can be explored in the outdoor realm. Interior architects have begun to re-appropriate issues and concerns sequestered within landscape architecture, and landscape scholars have begun to incorporate built works into their on-going inquiries. This new form of enquiry conveys an argument for interdependency rather than hierarchy.

\section{Conclusion: The Creation of a New Normal}

The concept of the Anthropocene has been gaining scholarly recognition both through its scientific legitimacy but also through its implications for the social sciences, humanities and the design disciplines. While the Anthropocene is providing the impetus for change, it is architects who need to create new ways for humans to inhabit their environments. Through immersion and extraction techniques with natural systems and processes, a new normal is being created within the disciplines of landscape architecture and interior architecture.

Providing solutions to the foreseeable problems related to climate change is essential to ensuring the survivability of the human race. Subsequently, creating a link between natural processes and unnatural technologies can be an answer to how we approach climate change. Harnessing invisible energies can result in greater efficiencies and reduce the dependency on non-renewable resources. In the light of the renewed critical possibilities associated with spatial experience, it is perhaps not surprising that "the embodied experience of space is back on the agenda" (Clarke 2011, 59).

Visceral spatial experience and the experience of empathy can be seen as central to the modernist understanding of architectural space as a plastic continuum defined by bodily experience. Incorporating the human scale is thereby crucial to creating environments which are enjoyable to live in and where the role of design is countered by 
embodied and embedded encounters. In the case study of cyborg interventions in the urban landscape of Auckland's waterfront, examples of man and nature and the impact of technology with generative and destructive forces, illustrates a pragmatic solution involving body, energy and surface through the lens of landscape architecture. This case also illustrates the blurring of disciplinary boundaries which the authors maintain is an important aspect of designing in the Anthropocene. Similarly, the remote case study of White Island illustrates the connections between generative and destructive forces; body, energy and surface; as man confronts the magnitude of nature. This forms a poetic brief for the incorporation of architectural technologies, highlighting moments of immersion and extraction.

The remaking of the future calls for alternative forms of enquiry across scales and sites of production. This paper highlights the role of interior and landscape architecture to jointly adapt to the imperatives of the Anthropocene and the emergence of energy both as pragmatic imperative and as poetic brief. The combination of interior architecture and landscape architecture, where the boundaries of interior and exterior are blurred, can be useful for the creation of physical manifestations to elicit a more poetic outcome in a multidisciplinary design-led framework as an act of intensification. Challenging the way that spaces are constructed through physical configuration need not be feared in the Anthropocene.

\section{References}

Addington, D. Michelle, and Daniel L. Schodek. 2005. Smart materials and new technologies: for the architecture and design professions. Oxford: Routledge.

Arnheim, Rudolf, Wolfgang M. Zucker, and Joseph Watterson. 1966. "Inside and Outside in Architecture: A Symposium." The Journal of Aesthetics and Art Criticism 25 (1): 3-15. https://doi.org/10.2307/428879

Auckland City Council. 2017 "GeoMaps". Accessed July 30, 2017.

https://geomapspublic.aucklandcouncil.govt.nz/view er/index.html

Benedikt, Michael. 2002. "Environmental stoicism and place machismo." Harvard Design Magazine.
Boas, Tobias, and Kate Marshall. 2014. "Writing the Anthropocene: An Introduction." Minnesota Review 83 (1): 60-72. https://doi.org/10.1215/002656672782243

Caan, Shashi. 2011. Rethinking design and interiors: Human beings in the built environment. London: Laurence King.

Cantrell, Bradley E., and Justine Holzman. 2015. Responsive landscapes: strategies for responsive technologies in landscape architecture. Abingdon: Routledge. https://doi.org/10.4324/9781315757735

Castree, N. 2014A. "The Anthropocene and Geography I: The Back Story." Geography Compass 8 (7): 436-449. https://doi.org/10.1111/gec3.12141

Castree, N. 2014B. "Geography and the Anthropocene II: Current Contributions." Geography Compass 8 (7): 450-463.

https://doi.org/10.1111/gec3.12140

Chakrabarty, Dipesh. 2009. "The Climate of History: Four Theses." Critical Inquiry 35 (2): 197-222. https://doi.org/10.1086/596640

Clarke, Joseph. 2011. "Wagnerism Embodied." Log 23: 59-69.

Clarke, N. 2011. Inhuman nature. London: Sage.

Dalby, Simon. 2014. "Rethinking geopolitics: Climate security in the Anthropocene." Global Policy 5 (1): 19. https://doi.org/10.1111/1758-5899.12074

Fernández-Galiano, Luis. 2000. Fire and memory: On architecture and energy. Cambridge: MIT Press.

Gissen, David. 2012. Subnature: Architecture's Other Environments. New York: Princeton Architectural Press.

Grosz, Elizabeth. 2017. "Time Matters: on temporality in the Anthropocene. - in conversation with Heather David and Etienne Turpin". Accessed July 21, 2017.

https://quod.lib.umich.edu/o/ohp/12527215.0001.0 01/1:14/--architecture-in-the-anthropoceneencounters-among-design?rgn=div1; view=fulltext

Gunderson, Lance H., and Lowell Pritchard, eds. 2012. Resilience and the behavior of large-scale systems. Vol. 60. Island Press. 
Johnston, Rosemary Ross. 2005. "Landscape as palimpsest, pentimento, epiphany: Lucy Maud Montgomery's interiorisation of the exterior, exteriorisation of the interior." CREArTA.

Johnson, Elizabeth, Harlan Morehouse, Simon Dalby, Jessi Lehman, Sara Nelson, Rory Rowan, Stephanie Wakefield, and Kathryn Yusoff. 2014. "After the Anthropocene: Politics and geographic inquiry for a new epoch." Progress in Human Geography 38 (3): 439-456. https://doi.org/10.1177/0309132513517065

Lally, Sean. 2009a. "Twelve Easy Pieces for the Piano." Architectural Design 79 (3): 6-11. https://doi.org/10.1002/ad.881

Lally, Sean. 2009b. "When cold air sleeps." Architectural Design 79 (3): 54-63.

https://doi.org/10.1002/ad.888

Lally, Sean. 2014. Air from Other Planets: A Brief History of Architecture to Come. Zurich: Lars Muller Publishers.

Lehman, Jessi, and Sara Nelson. 2014. "Experimental politics in the Anthropocene." Progress in Human Geography 38 (3): 444-447.

https://doi.org/10.1177/0309132513517065

Lewis, Simon L., and Mark A. Maslin. 2015. "Defining the anthropocene." Nature 519 (7542): 171. https://doi.org/10.1038/nature14258

Lokman, Kees. 2017. "Cyborg landscapes: Choreographing resilient interactions between infrastructure, ecology, and society." Journal of Landscape Architecture 12 (1): 60-73. https://doi.org/10.1080/18626033.2017.1301289

Moffitt, Lisa. 2013. "Thermodynamic Optimism: Three Energy/Material Dialogues." Edinburgh Architectural Research Journal 33: 57-64

Pallasmaa, Juhani. 2011. "An Architecture of the Seven Senses". In Weinthal, Lois, Toward a New Interior: An Anthology of Interior Design Theory, edited by Lois Weinthal, 40-49. New York: Princeton Architectural Press.

Parrott, Lael, and Wayne S. Meyer. 2012. "Future landscapes: managing within complexity." Frontiers in Ecology and the Environment 10 (7): 382-389. https://doi.org/10.1890/110082
Petrović, Emina Kristina, Bruno Marques, Natasha Perkins, and Guy Marriage. 2018. "Phenomenology in Spatial Design Disciplines: Could it Offer a Bridge to Sustainability?." In Advancements in the Philosophy of Design, pp. 285-316. Springer, Cham. https://doi.org/10.1007/978-3-319-73302-9_14

Power, Jacqueline. 2014. "The liminality of interiority: Australian indigenous cosmological space." In SITUATION Symposium and Exhibition, pp. 88-90.

Rahim, A. 2010. "Interiorities". Architectural Design 80 (3): 24-31. https://doi.org/10.1002/ad.1038

Rahm, P. “Jade Eco Park Taiwan”. Accessed June 1, 2017.

http://www.philipperahm.com/data/projects/taiwa $\mathrm{n} /$ index.html.

Rull, V. 2013. "A futuristic perspective on the Anthropocene." The Holocene 21 (5): 1-4.

Steffen, Will, Jacques Grinevald, Paul Crutzen, and John McNeill. 2017. "The Anthropocene: conceptual and historical perspectives." Philosophical Transactions of the Royal Society A: Mathematical, Physical and Engineering Sciences 369 (1938): 842867. https://doi.org/10.1098/rsta.2010.0327

Turpin, Etienne. 2014. Architecture in the Anthropocene: Encounters among design, deep time, science and philosophy. Michigan: Open Humanities Press.

https://doi.org/10.3998/ohp.12527215.0001.001

Weinthal, Lois. 2008. "Bridging the Threshold of Interior and Landscape: An Interview with Petra Blaisse." Architectural Design 78 (3): 64-71. https://doi.org/10.1002/ad.676

Yusof, K. 2013. “Geologic life: prehistory, climate, future in the Anthropocene." Society \& Space 31 (5): 779-795. https://doi.org/10.1068/d11512 